\title{
EL SEPULCRO DEL ARZOBISPO COMPOSTELANO DON RODRIGO DE LUNA EN IRIA FLAVIA
}

\author{
Por \\ MARTA CENDÓN FERNÁNDEZ
}

Entre los avatares que sacuden la Galicia del siglo XV, discurre la sobresaltada vida del arzobispo Don Rodrigo de Luna. Ya su instalación en la sede compostelana, fue conflictiva; el Cabildo había recibido una recomendación —-más bien imposición— para que eligiese por prelado a un sobrino del condestable Alvaro de Luna ${ }^{1}$, tras el fallido intento de instalarlo en la sede de Sevilla². La elección se llevará a cabo el 24 de marzo de 1449. Pero como el electo no tenía aun la edad canónica, se acordó suplicar al Papa que aprobase la elección, al tiempo que Alvaro de Luna, que ya había pretendido su instalación en la sede hispalense apoyado por el rey Juan $\mathrm{II}^{3}$, se dirigía directamente a Roma. Nicolas V lo nom-

\footnotetext{
' Era hijo de un primo de Don Alvaro, Juan de Luna, Comendador de Bamba y Prior de San Juan y Juana de Ardoz; véase LOPEZ FERREIRO, Antonio: Historia de la S.A.M.I. de Santiago de Compostela, Imp. y enc. del Seminario Conciliar Central, Santiago de Compostela, tomo VII, 1903, reed. Sálvora, 1983, p.193.

${ }^{2}$ MONTES ROMERO-CAMACHO, Isabel: «Un episodio de las relaciones Iglesia/ Estado en tiempos de Juan II: la postulación de Don Rodrigo de Luna como arzobispo de Sevilla», en Andalucía Medieval, Actas I Coloquio de Historia de Andalucía, Córdoba noviembre de 1979, Publicaciones del Monte de Piedad y Caja de Ahorros de Córdoba, Córdoba, 1982, pp.383-395.

${ }^{3}$ LOPEZ FERREIRO, Antonio: Don Rodrigo de Luna. Estudio histórico, Facsímil de la edición de 1884, Imprenta Paredes Espinosa, reed. Historia de Galicia, Edinosa, A Coruña 1991, p.7.
}

"CUADERNOS DE ESTUDIOS GALLEGOS", Tomo XLIV, Fascículo 109, Santiago 1997. 
bró administrador de la diócesis compostelana en espera de que cumpliese los 27 años, edad requerida para la prelacía, mediante una bula en la que expresa que se había reservado la provisión de la sede compostelana aún en vida de Don Álvaro de Isorna ${ }^{4}$. Su carrera eclesiástica había sido muy rápida, gracias a su parentesco con Alvaro de Luna, de tal modo que a los 24 años, ya era Capellán Mayor del rey, tesorero de la Iglesia de León y Notario Apostólico. Con él vinieron a Galicia algunos de sus familiares, pero también supo rodearse de importantes consejeros, muchos de ellos gallegos 5 .

Sin embargo más que su vida, ampliamente tratada por López Ferreiro, que le dedica incluso una monografía ${ }^{6}$, nos interesa su muerte y las razones para la conservación de su memoria en Iria Flavia. En realidad en torno a su figura se creó una «leyenda negra», que lo condenaba a un triste final. Baste recordar la opinión que merece al autor de la Silva Palentina:

«En las crónicas también se deuen escribir las malas hazañas como las buenas, porque unas nos convidan a la virtud y las otras nos refrenan de los vicios. Es de saber, que en este tiempo cerca del año MCCCCLVIII, era obispo de Santiago un Don Rodrigo de Luna, sobrino del maestre Don Aluaro de Luna, de quien antes hizimos mención. Este arzobispo era hombre muy vicioso, y hacía cosas muy feas $y$ deshonestas, $y$ entre otras hizo una harto escandalosa, que estando una donzella noble y muy hermosa el día de su boda en el tálamo, antes de la noche, el señor arzobispo parecióle que era bien celebrar él las bodas antes que el marido y vino allí a la casa con gente armada, y públicamente lleuó a la novia a su casa, donde la tuиo algunas noches sin quererla tornar a su marido: los padres se fueron a querellar al rey Don Enrique; el cual le mandó venir a su Corte, y estando él allí mientras el negocio se deliberaba, el conde de Trastámara Pero Alvarez Osorio y otros caualleros le tomaron sus villas y fortalezas, las cuales mientras vivió nunca pudo tornar a cobrar, y assi murió pobre y desheredado segúnd lo merecían sus desonestas costumbres» ${ }^{7}$.

${ }^{4}$ LOPEZ FERREIRO, A.: Historia..., op. cit., tomo VII, pp.190-1.

${ }^{5}$ LOPEZ FERREIRO, A.: Don Rodrigo..., op. cit., p.13.

${ }^{6}$ LOPEZ FERREIRO, A.: Don Rodrigo..., op. cit.

${ }^{7}$ FERNANDEZ DE MADRID, Alonso: Silva palentina, Excma. Diputación Provincial de Palencia, Palencia, 1976, p.307.

"CUADERNOS DE ESTUDIOS GALLEGOS", Tomo XLIV, Fascículo 109, Santiago 1997. 
Es verdad que su sepulcro no se halla en la catedral compostelana sino en la Colegiata de Iria Flavia (Padrón); sin embargo ello no supone tanto un destierro, como el resultado de diversos factores, entre los que cabe tener en cuenta que, si su parentesco con Alvaro de Luna lo llevó a relevantes puestos eclesiásticos, la caída del Condestable parece arrastrarlo a él también.

En sus últimas voluntades, leídas el 1-7-1460 en la Rochablanca de Padrón, Don Rodrigo manifestaba:

«Otrosi mandamos que nuestro cuerpo sea enterrado dientro en el cabildo viejo de la dicha nuestra iglesia de Santiago adonde tiene los pies el prelado quando esta en el abto del mandato el jueves de la çena poniendo ençima de la sepultura una piedra fegurada en ella nuestra persona revestida en avito pontifical et senon oviere lugar para ello mandamos que nuestro cuerpo sea enterrado en una capilla de las mayores de los monasterios de Santo Domingo o de San Françisco que son de fuera de la nuestra cibdad de Santiago a eleçion de nuestros conplidores et se a esto no oviere lugar mandamos que sea enterrado en la capilla mayor de Santa Maria Diria desta villa de Padron en la forma que dicha es» $(45 \mathrm{r}-45 \mathrm{v})^{8}$.

Realmente, a pesar de que presenta Padrón como tercera opción a la hora de ser inhumado, fueron numerosos los vínculos que le aproximan a dicha villa, en la que, por otra parte, falleció.

Así, estando en la Rochablanca, el 22-8-1456, año jubilar, funda en Padrón un hospital ${ }^{9}$, que se remata dos años más tarde; el 13-10-1458, en un documento dictado en Pontevedra, indica que el altar que hay en él,

\footnotetext{
${ }^{8}$ Archivo Catedral de Santiago, Leg. 161, Testamentos de sres. arzobispos 1448 a 1769, fols. 43r.-49v: «Testamento del Sr. Arzobispo don Rodrigo de Luna. Manda por el pagar al cabido ciertos maravedis que le debian, anno de $1460 »$.

${ }^{9}$ "Considerando, como el oficio de los Prelados es proveer e subvenir a las necesidades de los pobres, mayormente a los enfermos y peregrinos, e por quanto los fieles cristianos que con suma devoción por salvación de sus ánimas, visitan cada dia la nuestra Santa Iglesia de Santiago continuando sus romerias fasta la nuestra villa de Padron, e por defecto de buena ospitalidad, que no ha en la dicha nuestra villa, son fatigados y no reciben consolacion alguna[...]E porque nos y nuestra Mesa arçobispal tenemos y poseemos un territorio y suelo yermo y sin edificio en la dicha nuestra villa de Padron, que es propinquo a la iglesia de Santiago de la dicha nuestra villa, por ende, nos por
}

"CUADERNOS DE ESTUDIOS GALLEGOS", Tomo XLIV, Fáscículo 109; Santiago 1997. 
puede ser utilizado por cualquier clérigo, sin «perjudicio de la Iglesia madriz de Santa Maria d'Iria del Padron e de su derecho parrochial e funeral», encomendando la administración del hospital «a un canónigo de la dicha Iglesia de santa Maria d'Iria e a un home bueno e fixo del concejo de la dicha villa del Padron, ambos eligidos e escogidos e nombrados por los canónigos de la dicha Iglesia e jurados de la dicha villa» ${ }^{10}$.

En noviembre de 1457 se hallaba de nuevo en Iria, donde «seendo asentado no coro vaixo» de la Colegiata, declaró la autenticidad de una copia de un tumbo ${ }^{11}$.

Por otra parte, la reiterada presencia de sus escudos en la iglesia de Santiago de Padrón y en la cercana ermita de la Fuente de Santiago, indican su contibución a diversas obras de las mismas. Asimismo, tras la llamada del monarca al arzobispo y otros señores a acudir a la guerra de Granada, se produce un enorme malestar entre los caballeros gallegos, que se muestran reacios a partir. Don Rodrigo cumple la orden real, en tanto una parte de los canónigos, ante la intención de algunos nobles y determinados miembros del cabildo de expulsar al arzobispo, se retiran a Iria y se instalan en la Colegiata, hacia mediados de 1458, donde permanecerán dos años. A principios de octubre, Don Rodrigo de Luna regresa a Galicia, encontrando cerradas las puertas de Santiago, y la hostilidad de villas como Muros y Noya; sin embargo, Pontevedra, Padrón con su castillo de Rochablanca, la fortaleza de la Barreira y el castillo de Rochaforte, continuaban fieles, por lo que se instala en Pontevedra. Los conflictos se suceden, obligando incluso el prelado a trasladarse a Salamanca donde se hallaba en septiembre de $1459^{12}$, para regresar a finales de dicho año y, como indica en un documento de febrero de 1460 - en respuesta a ciertos requerimientos por parte de los canónigos cismáticos que habían perma-

\footnotetext{
servicio de Dios y honor del Santo Apostol Santiago, cuyo lugar tenemos, por nos y por nuestros subcesores para in perpetuum damos y deputamos el dicho territorio y suelo con todas sus pertinencias para que en él sea edificado y construido ospital y casa para recebimiento y consolacion de los pobres y peregrinos...», en LOPEZ FERREIRO, A.: Don Rodrigo..., op. cit., pp.23-4.

${ }^{10}$ LOPEZ FERREIRO, A.: Don Rodrigo..., op. cit., p. 26.

" LOPEZ FERREIRO, A.: Don Rodrigo..., op. cit., pp.27-8.

${ }^{12}$ Para todos estos sucesos véase LOPEZ FERREIRO, A.: Historia, op. cit., tomo VII, pp.210-33.
}

"CUADERNOS DE ESTUDIOS GALLEGOS", Tomo XLIV, Fascículo 109, Santiago 1997. 
necido en Santiago - tenía la intención de ir junto a los canónigos que estaban en Padrón ${ }^{13}$. Allí se instala en la Rochablanca para disponer los combates, pero fallece el 1 de julio, celebrándose los funerales en la Colegiata.

López Ferreiro supone que debió hacer el testamento en Salamanca por el otoño de 1459, nombrando testamentario al bachiller Gonzalo Núñez de Castro, vecino de dicha localidad, aunque no cita documento alguno ${ }^{14}$; sin embargo de la copia que existe en el Archivo de la catedral de Santiago se desprende que, ya enfermo, debió otorgar su testamento en Padrón, pues a la hora de elegir sepultura en Iria, dice «desta villa de Padron», lo que indica dónde estaba dictando sus últimas voluntades, en las que, por otra parte, no figura como testamentario Gonzalo Núñez de Castro ${ }^{15}$.

Los conflictos no cesaron a la muerte de Don Rodrigo de Luna, resultando muy problemática su sucesión ${ }^{16}$. Quizá por ello los restos del prelado ya no fueron trasladados a Compostela y se dejaron en la capilla mayor de la Colegiata de Iria, que tan bien lo había acogido. Por otra parte, como ha señalado Jerónimo del Hoyo, parece que allí yacían diversos obispos de Iria, lo que supondría el mantenimiento de un panteón de prelados ${ }^{17}$.

${ }^{13}$ LOPEZ FERREIRO, A.: Historia..., op. cit., tomo VII, pp.235-7.

${ }^{14}$ LOPEZ FERREIRO, A.: Historia..., op. cit., tomo VII, p.239. Ya en su obra sobre Rodrigo de Luna, op. cit., p.57, nota 2, congeturaba a partir de los datos que aportaba González Dávila, Pellicer o Martir Rizo, quienes señalaban como fecha del testamento el 9-7-1460, fecha en que ya se había producido el óbito.

${ }^{15}$ Véase documento antes citado.

${ }^{16}$ Véase toda la narración de acontecimientos en LOPEZ FERRERIO, A.: Historia..., op. cit., tomo VII, pp.241ss, y Galicia en el último tercio del siglo XV, Faro de Vigo, Vigo, 1968 ( $3^{\text {a }}$ ed. $)$, pp.15ss.

17 «Hay en esta iglesia, en la capilla mayor al lado del Evangelio un entierro llebantado con un bulto de piedra ensima con su mitra y cruz de lo mismo, y según paresce por unas letras questán en torno dél, es de don Rodrigo de Luna, arçobispo de Santiago; y a la entrada della, detrás del segundo pilar de la mano derecha, junto a él, por la parte del mediodía hay una sepultura sola, igual del suelo, con unas letras góticas grandes que no se leen por su antigüedad. Tiénese por tradición questán en ella enterrados veinte y ocho obispos de los que presidieron en ella; tiene quebrada una esquina la sepultura, dicen quiso un sacristán abrirla con codicia de hallar en ella algo de interés y que bió cierto resplandor y por él, y por haberse quebrado, dexó de proseguir su intento el dicho sacristán», en HOYO, Jerónimo del: Memorias del arzobispado de Santiago, 1607, Imprenta Moret, La Coruña, p.152.

"CUADERNOS DE ESTUDIOS GALLEGOS", Tomo XLIV, Fascículo 109, Santiago 1997. 
En el Tumbo viejo de aniversarios se expresa de este modo el fallecimiento del obispo: «Anno Domini MCCCCLX o primeiro dia de julio falesceu o arçobispo don Rodrigo de luna ena Rocha de Padron en dia martes» ${ }^{18}$.

No sabemos con certeza la fecha de realización del sepulcro de Don Rodrigo de Luna. Sin embargo tenemos diversos datos de sumo interés que permiten efectuar una aproximación a la misma. Así, el epitafio indica:

«SEPVLTURA. DEL. RIMO. SENOR. DON. R ${ }^{\circ}$ D. LVNA. ARCPBO. D. SCTIAGO. FALLESCIO. EN EL. MES. D. IVLLIO. ANO DE. M. CCCC. LX. ANOS ESTA. OBRA. MA(N)DO. FAZER. EL. HONRRADO. PEDRO DE SOTO. CARDENAL. CRIADO DE. SU. R. SENORIA.»

Además de lo que se puede deducir del testamento del prelado, donde se aprecia que no ha mandado realizar un monumento funerario, el epitafio aclara que el encargado de rendir culto a la memoria póstuma del prelado es Pedro de Soto, uno de los canónigos que están presentes en la redacción de sus últimas voluntades. Según recoge López Ferreiro «pasado algún tiempo el cardenal compostelano, Pedro de Soto, que había sido su familiar, recogió sus restos en un magnífico sarcófago de granito, cubierto de estatua yacente, vestida de hábitos pontificales, y colocado bajo un arco junto al altar mayor de la referida Colegiata ${ }^{19}$. El mismo autor, en su obra Historia de la S.A.M.I. de Santiago, hace constar en nota que actualmente se ve junto al altar mayor, pero que el presbiterio fue edificado de nuevo a fines del siglo XVII o principios del siguiente, por lo que parece plantear la duda sobre su ubicación primitiva ${ }^{20}$. No obstante, él mismo aporta una información que resulta capital para la datación del sepulcro. El cura de Santa Eulalia de Chacin, Ruy Vázquez, familiar del juez de Villestro, Fernán Rodríguez de Leira, escribe siete u ocho años después de la muerte del obispo:

${ }^{18}$ LOPEZ FERREIRO, A.: Don Rodrigo..., op. cit., pp.56-7; Historia..., op. cit., tomo VII, p.239.

${ }^{19}$ LOPEZ FERREIRO; A.: Don Rodrigo..., op. cit., p.57.

${ }^{20}$ LOPEZ FERREIRO, A.: Historia..., op. cit., tomo VII, pp.338-9, nota 1.

"CUADERNOS DE ESTUDIOS GALLEGOS", Tomo XLIV, Fascículo 109, Santiago 1997. 
«E o Arçobispo de Santiago don Rodrigo de Luna, último pasado, que y jaz sepultado dentro do arco das gradizelas do altar mayor de Santa Maria de Iria. O qual pasou moitos traballos en guerras con os cabaleiros de seu arçobispado, e con os cidadaos desta cibdad de Santiago. Outrosi con o Conde de Trastámara que se apoderou ena cidade. Por lo qual él indo a mandado de noso señor el Rey, se leuantaron contra él non lle querendo obedescer por señor; por los pedidos grandes que el deitara ena cidade e villas e lugares, desasperaron dél. Esto foi ena era de MCCCCLVIIII anos».

Este texto, además de corroborar los datos que ya se han comentado sobre las sublevaciones contra el arzobispo, permite conjeturar la posibilidad de que el sepulcro ya estuviese realizado en época de Ruy Vázquez, pues dice que «y jaz sepultado dentro do arco»; por una parte, nos habla de yacer; por otra, dentro de un arco, lo que parece referirse a, «bajo un arcosolio» y consiguientemente se trataría de un sepulcro adosado. Sería extraño un simple enterramiento en el suelo, bajo un arco, con lo que se puede pensar en una imagen yacente cobijada por un arco, tal como hoy se conserva. Aún más, al mencionar «das gradizelas do altar mayor», indicaría que la ubicación originaria se corresponde con la actual, en la zona del presbiterio que da paso a la nave (Lám.1).

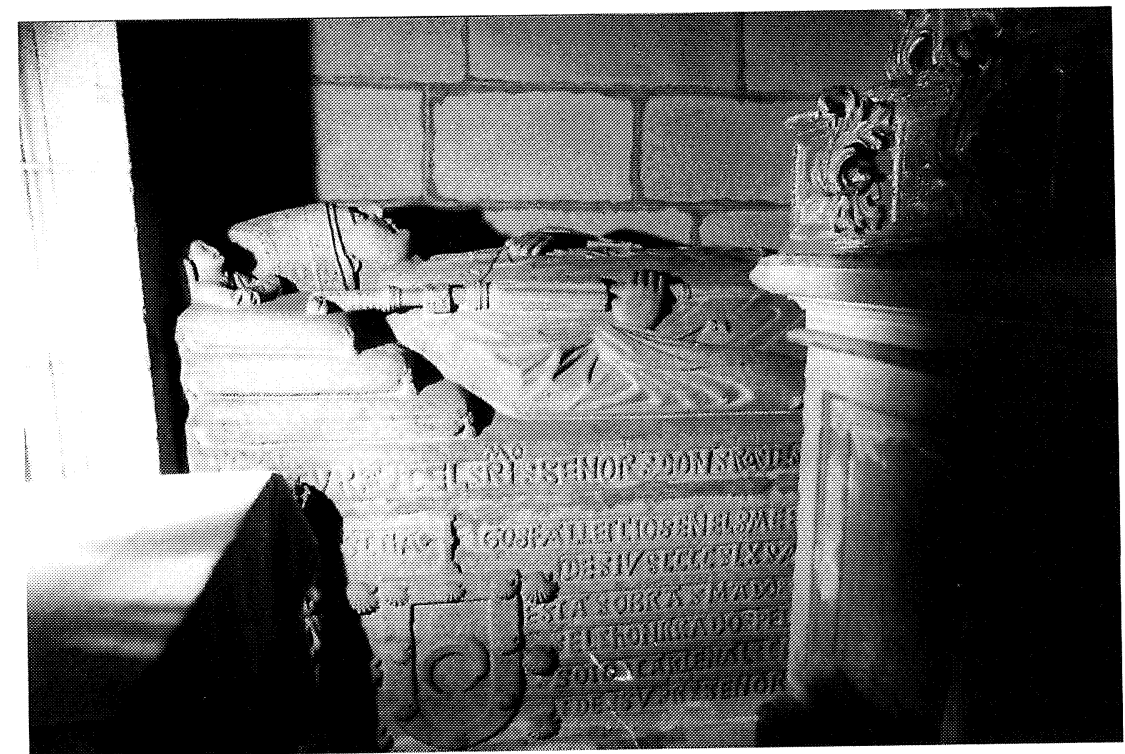

Lám. 1. Conjunto sepulcral de Don Rodrigo de Luna en la Colegiata de Iria.

"CUADERNOS DE ESTUDIOS GALLEGOS", Tomo XLIV, Fascículo 109, Santiago 1997. 
Con esos datos se puede pensar que el sepulcro se habría realizado hacia mediados de la década de los 60. Si se tienen en cuenta las características estilísticas, es posible establecer relaciones con otros ejemplos que se harían en fechas próximas. Chamoso, indica que el sepulcro del obispo de Orense, Don Alonso López de Valladolid, que se halla en la catedral compostelana, sería de la «misma inspirada mano» que había labrado el del arzobispo Don Rodrigo de Luna ${ }^{21}$, así como el del arcediano Don Juan Mariño de Sotomayor ${ }^{22}$. Núñez, ratifica la opinión de Chamoso a la que añade la posibilidad de que se pueda atribuir a la misma mano, el sepulcro del Mariscal Suero Gómez de Sotomayor, o, en su defecto, a un escultor que pudo formarse en la tradición del que podría denominarse «Maestro de los sepulcros de dignidades eclesiásticas» ${ }^{23}$. Para ello se basa en las semejanzas que ofrecen ambos sepulcros: «el mismo tipo de almohadón de prelado, escalonado y rematado en borlas que promueven arrugas en el punto de unión de los cabos deshilachados. En cuanto al macizo facial de ambos, revela una atención a un planteamiento plástico muy afín, con una nariz (muy desgastada y quebrada en la figura del Mariscal) que pasa sin transición a la frente, acusados pómulos y orbicular de los labios distendida hacia los músculos cigomáticos, como acusados son asimismo los músculos orbiculares de los párpados y los ojos aovados que parecerían representar a los yacentes en actitud de sueño. Finalmente, el pabellón auricular del acusado lóbulo» ${ }^{24}$. Asimismo, sin descartar una autoría común para el del arcediano Don Juan Mariño de Sotomayor, fallecido en 1496, sitúa la ejecución de éste último hacia $1480^{25}$. Por su parte Manso basándose en la opinión de Moralejo, indica que «la expresión risueña del rostro, la sonrisa boba y los ojos vidriosos se vinculan con el tímpano de la Anunciación y Epifanía de Santa María de Vigo, y con el retablo de san Gregorio y los enterramientos de Vilar de

\footnotetext{
${ }^{21}$ CHAMOSO LAMAS, Manuel: Escultura funeraria en Galicia, Instituto de estudios orensanos «Padre Feijoo», Orense 1979, p.447.

${ }^{22}$ CHAMOSO LAMAS, M.: Escultura..., op. cit., p.227.

${ }^{23}$ NUÑEZ RODRIGUEZ, Manuel: La idea de inmortalidad en la escultura gallega, Excma. Diputación Provincial de Orense, Orense, 1985, p.80.

${ }^{24}$ NUÑEZ RODRIGUEZ, M., op. cit., p.79.

${ }^{25}$ NUÑEZ RODRIGUEZ, M., op.cit., p.81.

"CUADERNOS DE ESTUDIOS GALLEGOS", Tomo XLIV, Fascículo 109, Santiago 1997.
} 


\section{Donas» $^{26}$.}

Ciertamente, el sepulcro de Don Rodrigo de Luna se haría en primer lugar y tras él se llevaría a cabo el del obispo de Orense, Don Alonso López de Valladolid (Lám.2), promovido para dicha sede en 1466. A continuación, aunque años más tarde, se esculpiría otra de las obras atribuibles sin duda a este taller, cual es, el sepulcro del arcediano Don Juan Mariño de Sotomayor (Lám.3) que guarda más semejanzas con el sepulcro del arzobispo compostelano que con el del prelado orensano. El del arcediano presenta una factura más geométrica, mantiene el ángel junto a la almohada, un rostro más modelado y una mitra de pico más corto.

En lo que atañe al sepulcro de Don Rodrigo de Luna, consta de yacente y yacija con una inscripción y el escudo del prelado (véase Lám.1). Presenta dos peculiaridades con respecto a otros ejemplos del mismo taller; una, propia de su condición de arzobispo: el palio, que se ornamenta con elementos en forma de «tau» y algunas rosetas (Lám.4), a la que se añade otra, característica de la sede compostelana y que se documenta desde el pontificado de Pedro Suárez de Deza (1173-1206): el remate del báculo en forma de «tau» (Lám.5).

Por lo demás, el yacente viste el habitual atuendo episcopal. Sobre el alba parece que se dispone una dalmática, si bien su ubicación actual, con un retablo adosado no permite su visión lateral completa, que se tiene que suplir con una superior desde la que parece apreciarse una vestidura más corta que el alba, e incluso otra más que podría corresponder a la sobrepe1 liz (Lám.6). No obstante, bajo la casulla se observa una manga ancha de tela fina, a juzgar por su factura pinjante, rematada en una borla (Lám.7), semejante a la que remata los guantes en el ejemplo de Don Alonso López de Valladolid. La casulla, de tela gruesa que genera pliegues acartonados, se decora con red de rombos, al igual que la mitra en la que se disponen rosetas similares a las del palio. Bajo la mitra, al igual que en el ejemplo de Don Alonso López de Valladolid y en el del arcediano Don Juan Mariño, se observa un casquete que tapa parte de la oreja (Lám.8).

${ }^{26}$ MANSO PORTO, Carmen: «El sepulcro de Suero Gómez de Sotomayor en Santo Domingo de Pontevedra», en El Museo de Pontevedra, tomo XLIV, Pontevedra 1990, p.395, lo cual repite en Arte gótico en Galicia: los dominicos, tomo II, Fundación Pedro Barrié de la Maza, Conde Fenosa, La Coruña 1993, p.515.

"CUADERNOS DE ESTUdIOS GALLEGOS", Tomo XLIV, Fascículo 109, Santiago 1997. 


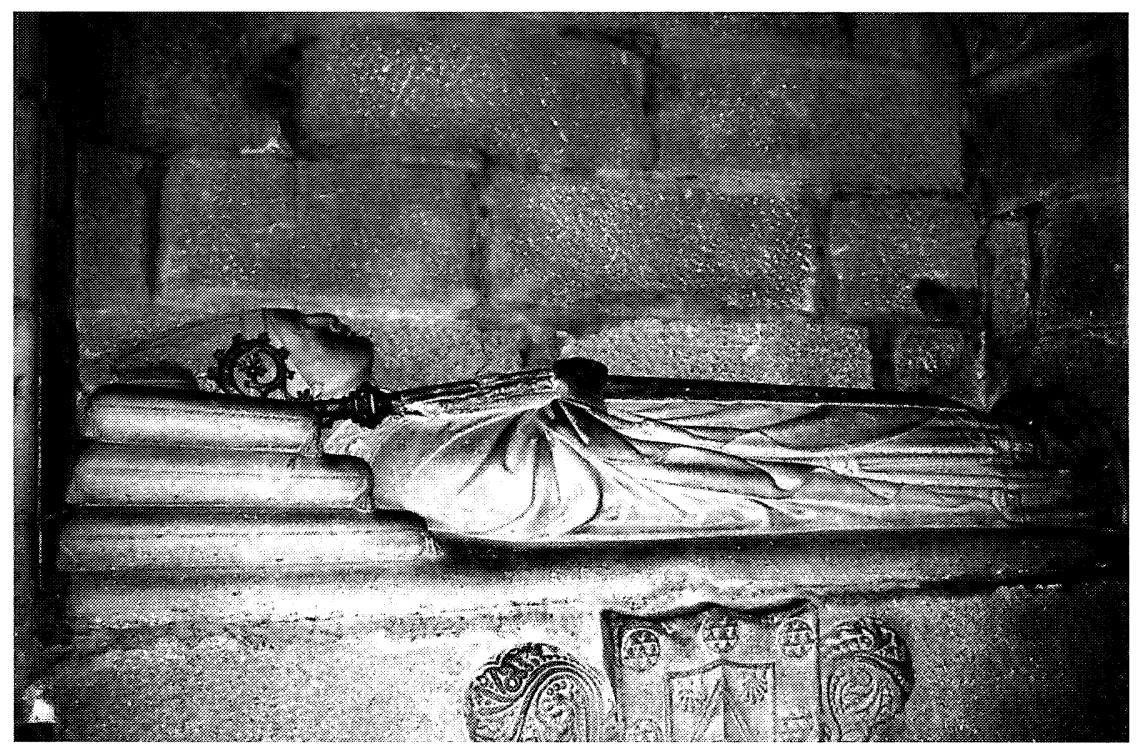

Lám. 2. Yacente del obispo de Orense Don Alonso López de Valladolid, en la catedral de Santiago.

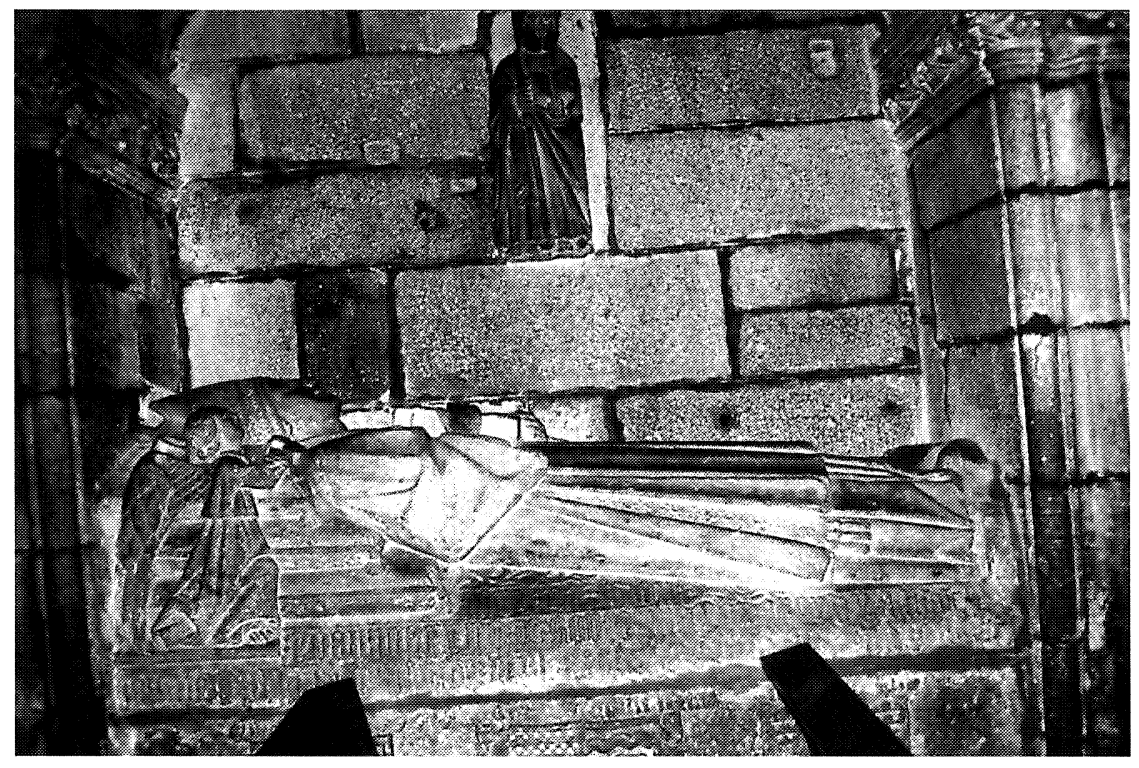

Lám. 3. Yacente del arcediano Don Juan Mariño de Sotomayor en Vilaxoán (Pontevedra). 


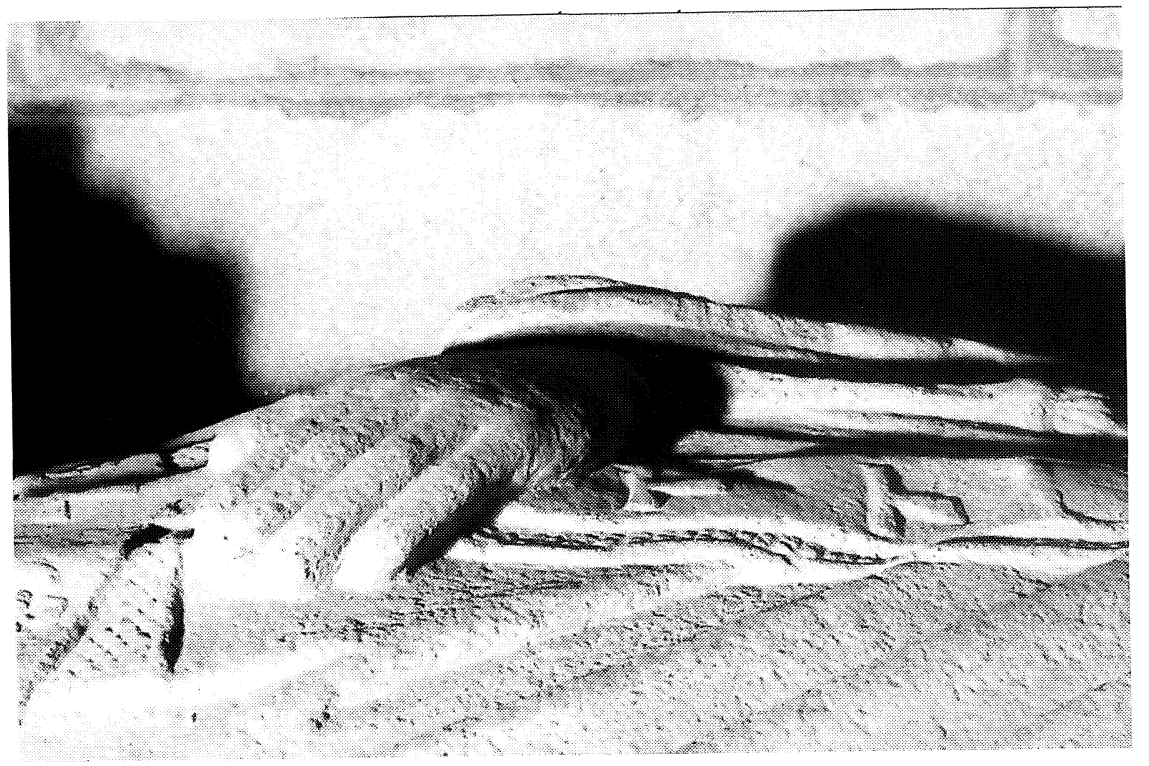

Lám. 4. Sepulcro de Don Rodrigo de Luna. Palio.

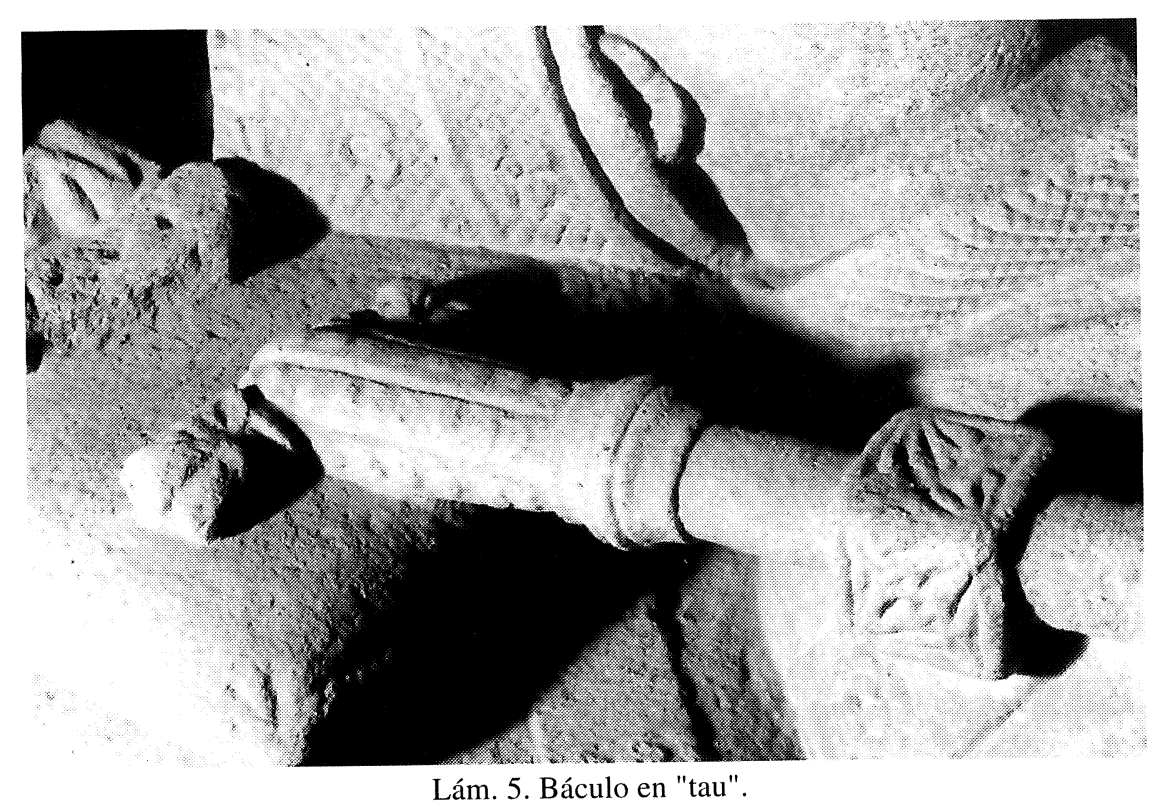

(c) Consejo Superior de Investigaciones Científicas 


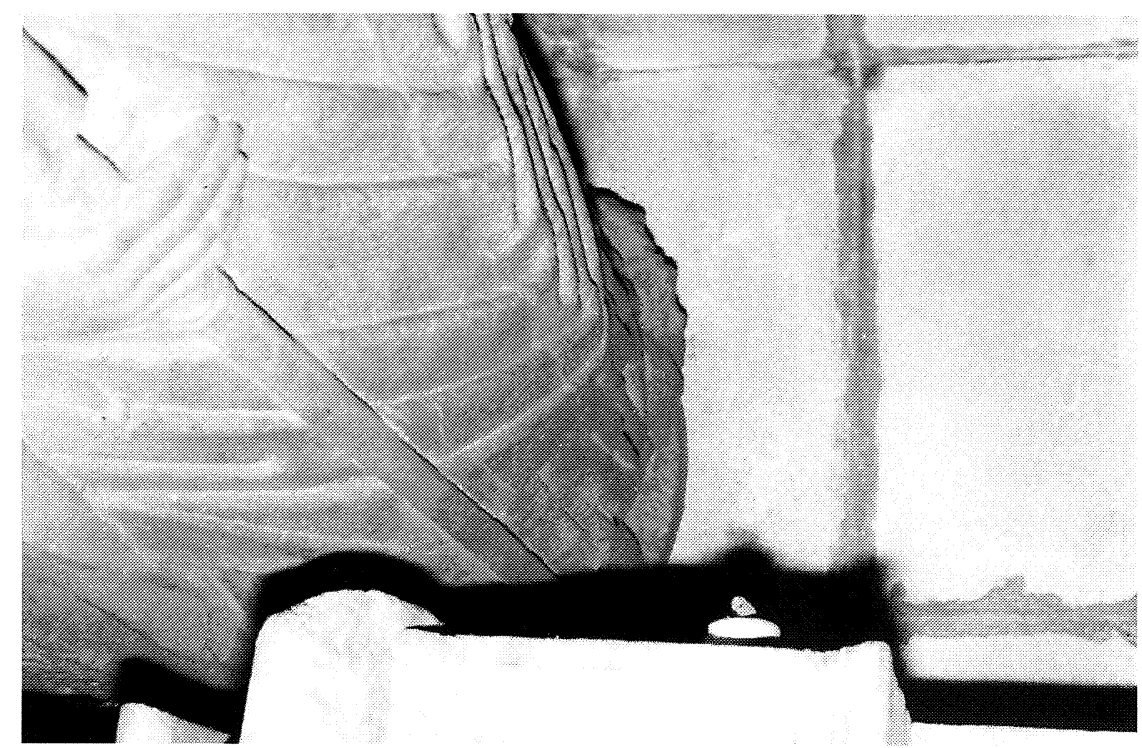

Lám. 6. Parte inferior del yacente.

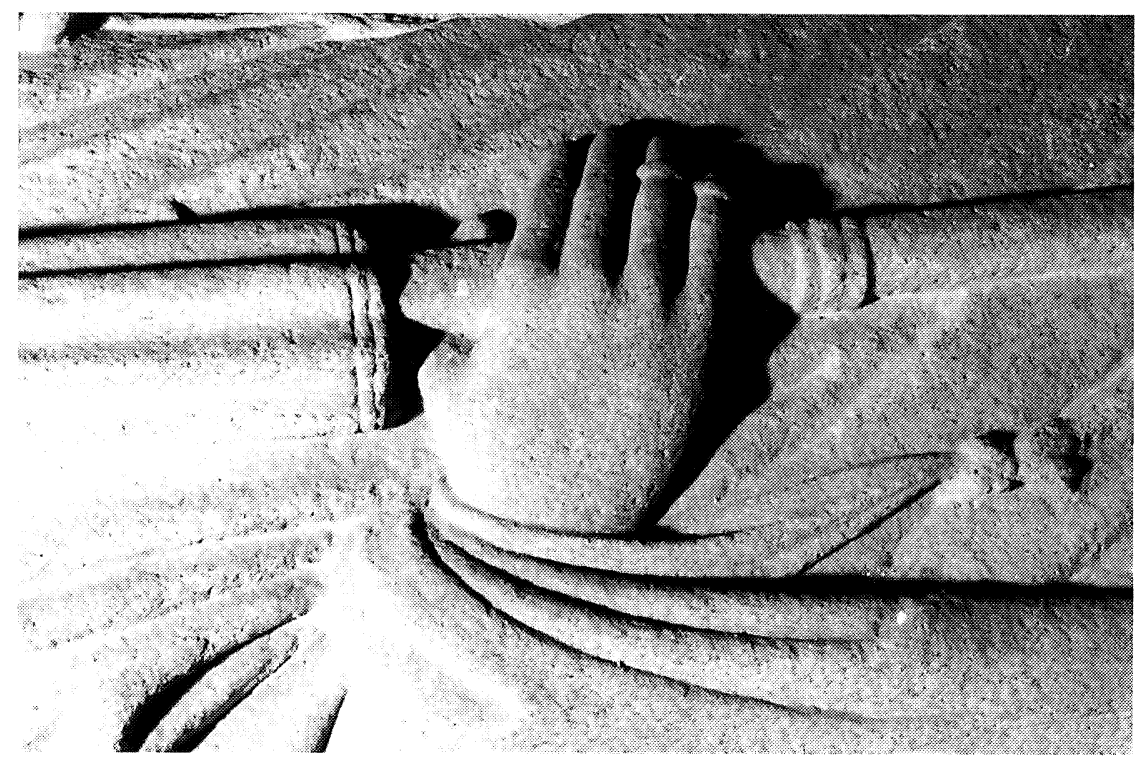

Lám. 7. Detalle. Mano derecha. 


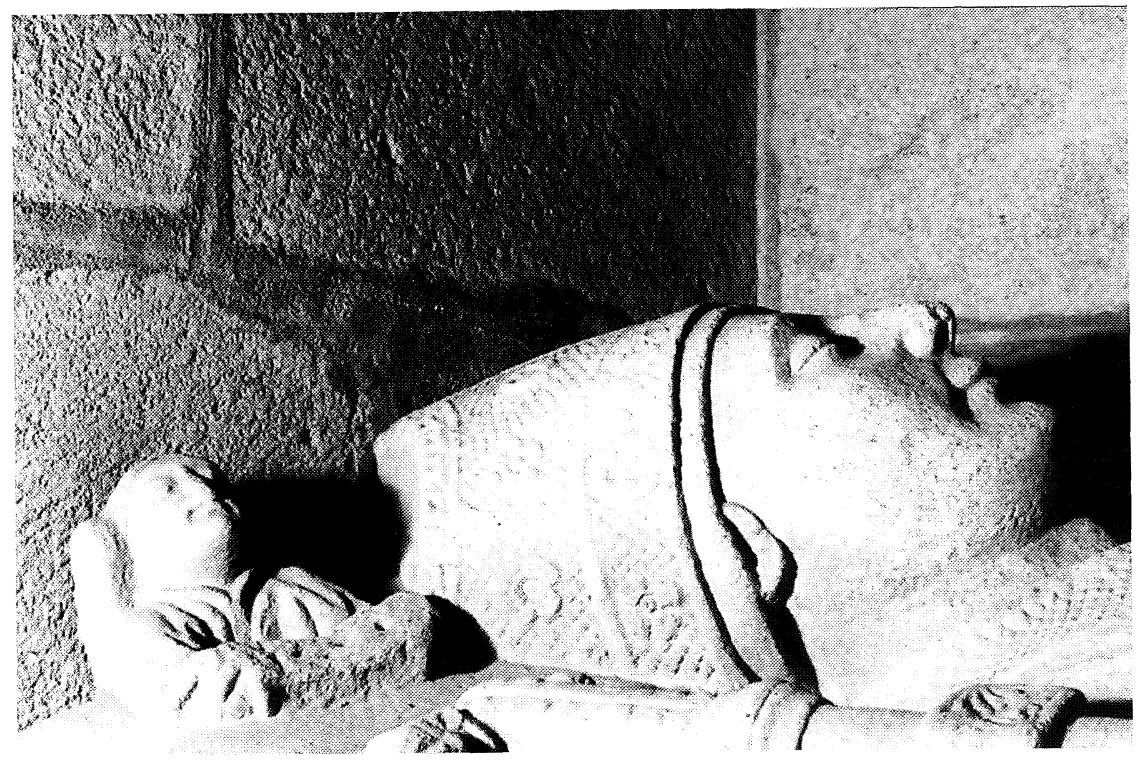

Lám. 8. Mitra.

Los ornamentos litúrgicos se complementan con el manípulo que pende de la mano izquierda y remata en fleco; la estola que parece intuirse en la parte inferior; el amito que se aprecia en torno al cuello; los guantes sobre los que se colocan sendos anillos en los extremos de los dedos anular y meñique; finalmente las sandalias, decoradas con red de rombos (Lám.9).

Cabe también destacar, el báculo; para él se sigue el modelo del que porta el Santiago del parteluz del Pórtico de la Gloria, con dos cabezas de león en los extremos de la empuñadura, patrón que ya había sido utilizado en otros ejemplos como el de la Reina Santa, Isabel de Portugal ${ }^{27}$, o el del arzobispo Don Alonso Sánchez de Moscoso y que se correspondería con el que utilizaban los prelados. Sin embargo, en este caso, el asta no se decora con conchas como ocurría en los ejemplos de Bernardo II - inhumado en Santa María de Sar-, Santa Isabel de Portugal o Don Alonso Sánchez de Moscoso; pero en la parte superior, bajo la empuñadura, se

${ }^{27}$ MORALEJO ALVAREZ, Serafín: «Báculo de Santa Isabel de Portugal», en Santiago, camino de Europa. Culto y cultura en la peregrinación a Compostela, catálogo de exposición, Santiago de Compostela 1993, nº126, pp.434-5.

"CUADERNOS DE ESTUDIOS GALLEGOS", Tomo XLIV, Fascículo 109, Santiago 1997. 


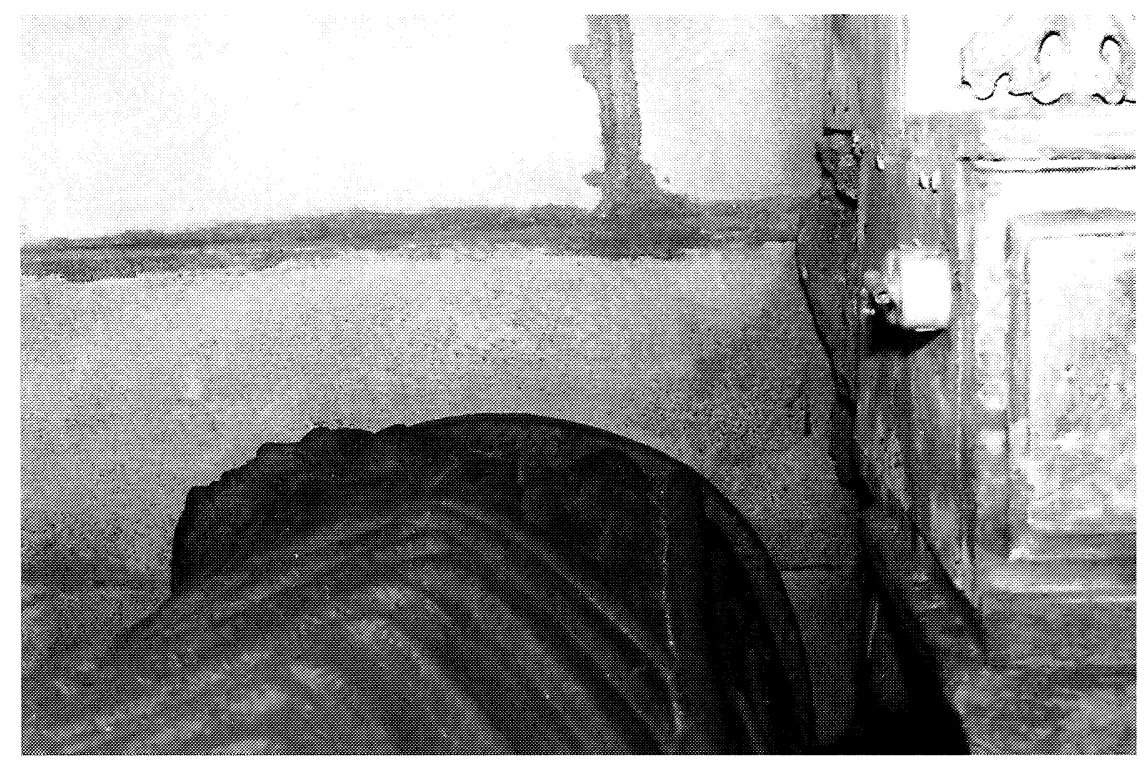

Lám. 9. Sandalias.

coloca una pieza cúbica decorada con incisiones que evocan el trabajo de orfebrería, tras la cual se dispone un panisellus muy corto, de tal modo que la mano del prelado ase directamente el asta.

Otro elemento digno de reseñar es la presencia de ángeles insertos entre las almohadas; entre sus manos se abre un libro, con todo el simbolismo que ello entraña, dentro de las oraciones por el alma del difunto. Su rostro es redondeado, con un cabello muy pegado a la cabeza al igual que las alas que se adhieren al cuerpo, constreñidas por la falta de espacio. Sus rasgos son muy semejantes a los que aparecen en el sepulcro del arcediano Don Juan Mariño, aunque en este último su ubicación en el lateral, permite un despliegue de alas que después se vuelven sobre si mismas, incluso en el que se corresponde con la parte adosada al muro.

Si se observa la composición general del yacente de Don Rodrigo de Luna, cabe tener en cuenta, en primer lugar, el rostro (véase Lám.8). Los ojos se cierran quedando muy marcada la línea entre los párpados, proporcionando a la figura un aspecto de sueño plácido, o «muerte-sueño» (Núñez), mientras esboza una leve sonrisa. A diferencia de las facciones que presenta el ejemplo de Don Alonso López de Valladolid de aspecto redondeado, con un tratamiento superficial del bloque, donde la boca es

"CUADERNOS DE ESTUdiOS GALLEGOS", Tomo XLIV, Fascículo 109, Santiago 1997. 
casi una línea recta, o el mentón una curva, en el caso de Don Rodrigo de Luna los planos son más trabajados, con incisiones más profundas como se aprecia en las fosas nasales o en los hoyuelos que se forman en las comisuras de unos labios bien delimitados, y que generan, a su vez, una barbilla de cierta convexidad, semejante al rostro que muestra el arcediano inhumado en Vilaxoán.

En lo que respecta a la gestualidad, es semejante a la que muestra el yacente de Don Alonso López de Valladolid: la mano derecha sujeta el báculo, mientras la izquierda se coloca extendida sobre el pecho; cabe recordar, una posición semejante en el yacente del obispo de Tuy, Don Juan Fernández de Sotomayor (II). Sin embargo, en el de Don Rodrigo de Luna, la mano derecha agarra el báculo más abajo, de manera que la composición se abre, y la figura parece que se vuelve un poco hacia el espectador que así puede apreciar parte del cuerpo, la otra mano, el palio y el manípulo. Asimismo a diferencia de los ejemplos mencionados, la figura resultaría cortada si se pusiese de pie: los pliegues de la casulla, en el brazo derecho, rematan sobre una superficie totalmente lisa, y el codo se apoya sobre el plano de base.

Finalmente cabría destacar que, al igual que en otros ejemplos del mismo taller, la figura descansa sobre una base la cual, en su extremo izquierdo, hoy mutilado, parece que contaba con un ángel con libro, tal como indica Chamoso ${ }^{28}$ (véase Lám.9). No obstante, dada su ubicación actual resulta difícil comprobarlo y, por otra parte, es preciso indicar la tendencia de este autor a dejar sin rematar el pie izquierdo, lo que podría tratarse de un efecto similar de economía, ya que es la parte correspondiente al ángulo que se adosa al muro.

En lo que atañe a la yacija destaca, por una parte, la inscripción, que se adapta al espacio disponible, variando la longitud de las líneas, e incluso interrumpiéndose para dejar paso a los elementos del escudo el cual curiosamente no se sitúa en el centro. Este consta del menguante de los Luna con bordura en la que reparten ocho veneras, motivo que en grupo de tres, flanquea el escudo ${ }^{29}$ (Lám.10). Por otra parte destaca un prótomo de león que sirve como soporte, y que hace suponer la pérdida de otro. En

${ }^{28}$ CHAMOSO LAMAS, M.: Escultura..., op.cit., p.447.

${ }^{29}$ CHAMOSO LAMAS, M.: Escultura..., op.cit., p.445.

"CUADERNOS DE ESTUDIOS GALLEGOS", Tomo XLIV, Fascículo 109, Santiago 1997. 


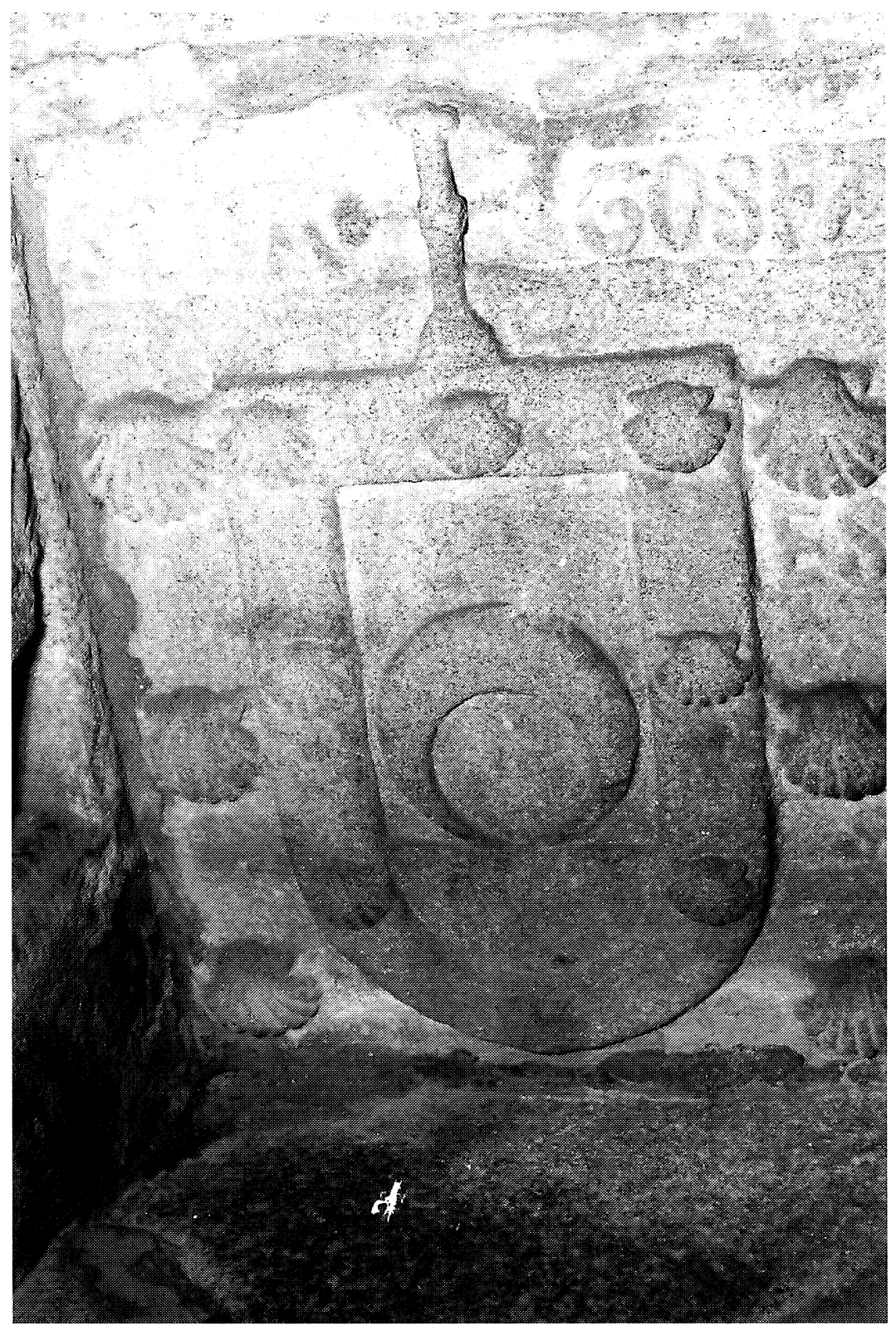

Lám. 10. Escudo de Don Rodrigo de Luna en la yacija. 


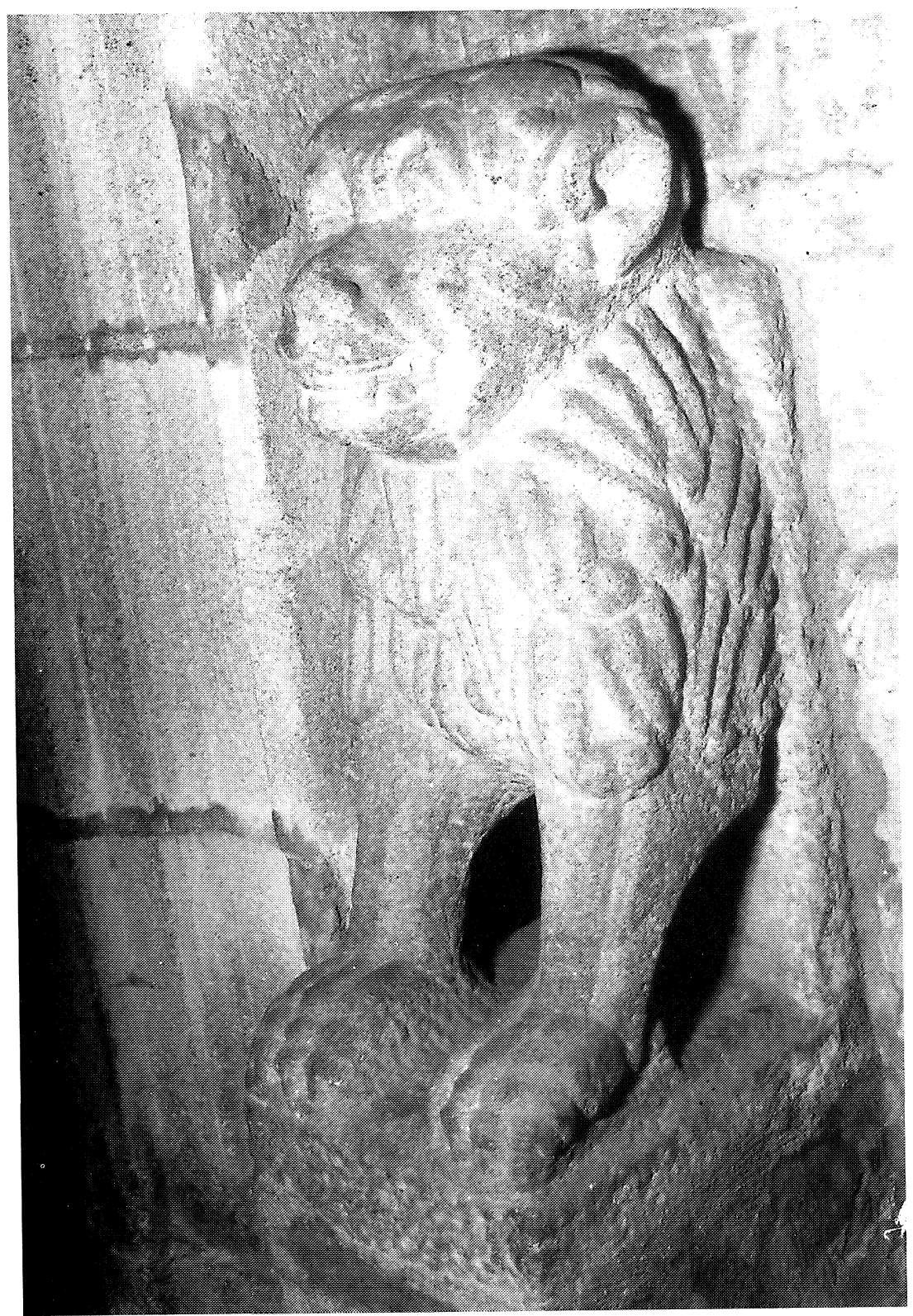

Lám. 11. León que soporta la yacija. 
realidad, a pesar de sus fauces leoninas, el conjunto de la cabeza, con grandes orejas, cobra un aspecto simiesco, en tanto que se marca el pelaje del cuerpo y afiladas garras que reposan sobre un pedestal (Lám.11). Su factura es muy similar a la de los soportes del sepulcro del arcediano Don Juan Mariño, si bien en dicho caso están echados e incluso uno de ellos gira la cabeza.

El conjunto sepulcral de Don Rodrigo de Luna fue conservado a pesar de las obras que llevaron a sustituir la antigua iglesia románica por la actual en el siglo XVII. Es evidente que por ese motivo, sufrió un traslado de tal manera que el arco que hoy lo cobija no corresponde al primitivo enterramiento. Sin embargo, a diferencia de lo que parece indicar Chamoso - cuando señala «consérvase uno de los leones que soportaron el arca antes de su traslado ${ }^{30}$, de lo que podría deducirse que el sepulcro era exento- su tratamiento, así como los datos documentales a los que se ha hecho referencia, y la comparación con otros ejemplos del mismo taller, parecen confirmar que se trató, desde el principio, de un sepulcro adosado.

En definitiva, se trata de un ejemplo perteneciente a un taller que realiza diversos sepulcros de eclesiásticos que se vinculan con Compostela, si bien cada uno de ellos se ubicará en un emplazamiento diferente. El del arzobispo compostelano en Iria, en consonancia con la propia leyenda negativa que rodeó a este prelado, parecería reflejar, incluso más allá de su muerte, un cierto destierro. En realidad ni los cronistas próximos, como Ruy Vázquez, ni su sepulcro, parecen corroborar ese final que casi lo condenaba a damnatio memoriae; al contrario, su recuerdo fue exaltado en un conjunto sepulcral, en el que el epígrafe evoca su persona, y diversos elementos iconográficos, como el báculo en «tau», insisten en su vinculación con Santiago, en una ciudad, Iria, de profunda raigambre jacobea.

\footnotetext{
${ }^{30}$ CHAMOSO LAMAS, M.: Escultura..., op. cit., p.445.
} 